\title{
Particulate and Dissolved Black Carbon in Coastal China Seas: Spatiotemporal Variations, Dynamics, and Potential Implications
}

\author{
Yin Fang, Yingjun Chen,* Guopei Huang, Limin Hu, Chongguo Tian, Jingqian Xie, Jun Lin, \\ and Tian Lin*
}

Cite This: Environ. Sci. Technol. 2021, 55, 788-796

Read Online

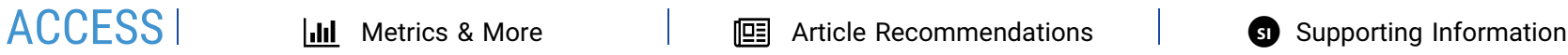

ABSTRACT: Elaborating the spatiotemporal variations and dynamic mechanisms of black carbon (BC) in coastal seas, the geographically pivotal intermediate zones that link the terrestrial and open oceanic ecosystems, will contribute significantly to refine the regional and global $\mathrm{BC}$ geochemistry. In this study, we implemented a large spatial-scale and multiseason and -layer seawater sampling campaign in high BC emission influenced coastal China seas (Bohai Sea and Northern Yellow Sea) and quantified the thermal/optical reflectance-based particulate $\mathrm{BC}$ (PBC) and benzene polycarboxylic acids-based dissolved $\mathrm{BC}$ (DBC). We found that the climate and its associated hydrological effects (including the intensive resuspension and coastal current transport) largely regulate both $\mathrm{PBC}$ and $\mathrm{DBC}$ spatiotemporal variations and dynamics. In combination with previous work on upstream rivers and downstream open ocean, a significant and continuous decrease in the DBC aromatic condensation was observed along the river-to-ocean continuum, probably due to the increment of the photochemical degradation during the waterborne transport. Based on our DBC methodological development, i.e., the determination and subsequent inclusion of the nitrated BC molecular markers, the magnitudes of the current global DBC fluxes and pools were updated. After the update, the DBC fluxes from atmospheric deposition and riverine delivery were estimated at rates of 4.3 and $66.3 \mathrm{Tg} \mathrm{yr}^{-1}$, respectively, and the global oceanic DBC pool was approximately $36 \mathrm{Gt}$. This update will greatly assist in constructing a more robust regional and global $\mathrm{DBC}$ and $\mathrm{BC}$ cycling and budgets.

\section{INTRODUCTION}

Coastal seas are the geographically pivotal intermediate zones that link terrestrial and open oceanic ecosystems. ${ }^{1,2}$ Organic carbon (OC) cycling in coastal seas has been identified as a dynamic and disproportionally crucial component in the global carbon cycling and budgets. ${ }^{1-4}$ Black carbon (BC) is the thermally altered $O C$ generated exclusively from the incomplete combustion of organic matter, including biomass and fossil fuels. ${ }^{5,6}$ It represents a complicated combustion continuum, spanning from large pieces of char/charcoal to submicron-sized soot particles. ${ }^{7-9}$ Due to the differences in the formation conditions (e.g., temperatures), the physical and chemical properties of $\mathrm{BC}$ vary significantly along the continuum. BC has recently received increasing attention due to its remarkably different biogeochemical implications from other fractions of bulk $\mathrm{OC}$ and the realization that $\mathrm{BC}$ plays much more dynamic roles in the global carbon cycle than previously thought. ${ }^{9-11}$ It is thus of great importance and necessity to refine the $\mathrm{BC}$ cycle, especially in coastal areas characterized by high $\mathrm{BC}$ emission intensity, such as the coastal China seas. ${ }^{2,12,13}$

China, with a gross population of 1.36 billion in East Asia, is widely recognized as the world's largest $\mathrm{BC}$ emitter. ${ }^{12,14}$ The regions in Bohai Rim, consisting of the five provinces/ municipalities of Liaoning, Hebei, Shandong, Beijing, and Tianjin (Figure 1a), rank not only the domestic but also the world's highest $\mathrm{BC}$ emission intensity. ${ }^{12,14}$ Specifically, these regions account for merely $5 \%$ of the Chinese mainland but contribute over $20 \%$ of China's total BC emission. ${ }^{12}$ Due to the integrated influences of the prevailing northerly/northwesterly winter East-Asian monsoon and large amounts of riverine discharge (such as the Yellow River (YR), Figure 1b), a significant quantity of $\mathrm{BC}$ produced in Bohai Rim can be easily mobilized into the adjacent Bohai Sea (BS) and Northern Yellow Sea (NYS), rending them important BC reservoirs. $^{2,13,15}$

Increasing evidence has revealed that BC could experience biotic and/or abiotic oxidation in soils and photo-oxidation in the atmosphere. ${ }^{16-23}$ These oxidation processes increase the number of oxygen-containing functional groups and overall polarity for it to become soluble enough to be transferred to

Received: September 22, 2020

Revised: November 10, 2020

Accepted: November 12, 2020

Published: December 4, 2020

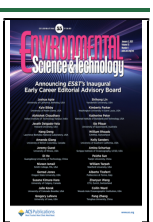




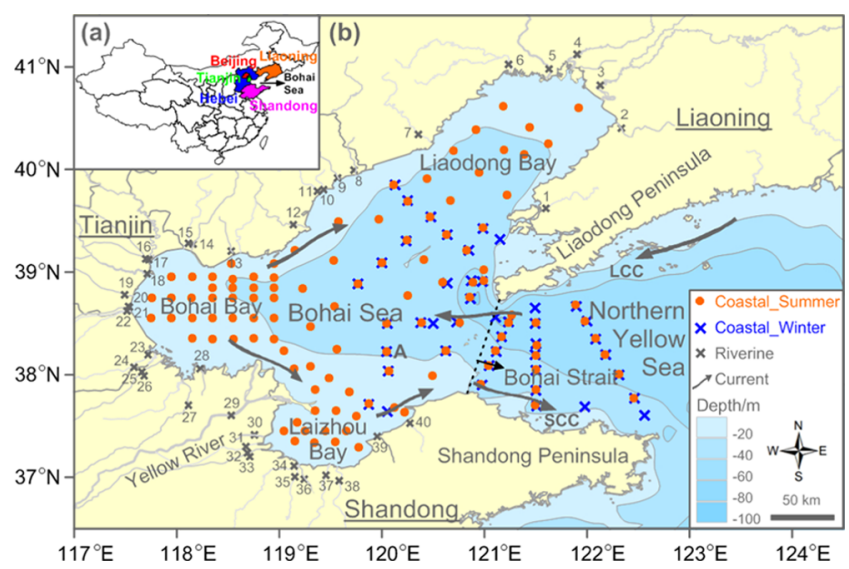

Figure 1. Map illustrating the study area and sampling sites. (a) Riverine data are referenced from Fang et al. ${ }^{2}$ (b) SCC and LCC denotes the Shandong Coast Current and Liaonan Coast Current, respectively. ${ }^{58,59}$

the dissolved phase, i.e., the dissolved $\mathrm{BC}$ (DBC). To date, there have been numerous studies regarding particulate $B C$ (PBC) on the regional atmosphere, soils, rivers, wetlands, and marine sediments in the Bohai Rim. 2,13,15,22,24-28 Unfortunately, however, the available studies have drawn little attention to the $\mathrm{PBC}$, let alone the analytically challengeable DBC in coastal seawater, ${ }^{29}$ which is an essential passage/ matrix for BC transfer among these major reservoirs. ${ }^{9,30}$ This spatial and componential gap might to a large extent result in our partial understanding of the process-based $\mathrm{BC}$ behaviors, such as the migration and transformation of the DBC from its upstream rivers to downstream open ocean..$^{5,6,31,32}$ To address this geochemically important question, we implemented a large spatial-scale and multiseason and -layer seawater sampling campaign in high-intensity BC emission influenced coastal BS and NYS. We simultaneously quantified and discussed both the $\mathrm{PBC}$ and $\mathrm{DBC}$, with more emphasis on DBC geochemistry.

The major objectives of the present study were (1) to uncover the spatiotemporal variations and dynamics of both $\mathrm{PBC}$ and DBC in coastal BS and NYS; (2) together with previous work on rivers and the open Pacific Ocean, ${ }^{2,31}$ to elucidate the molecular transformation of the DBC during river-to-ocean continuum transport; and (3) to update the magnitudes of current global atmospheric and riverine DBC fluxes and oceanic DBC pools based on our DBC methodological development. In comparison with the previous method, ${ }^{33}$ our modified DBC method not only significantly eliminates the complicated pretreatments, such as the derivatization (methylation/silylation) and sample cleanup after the $\mathrm{HNO}_{3}$ digestion, but can also quantify the nitrated molecular markers of the DBC (i.e., the nitrated benzene polycarboxylic acids, $\mathrm{NO}_{2}$-BPCAs), which were not involved by most of the previous $\mathrm{DBC}$-associated investigations. ${ }^{9,10,34-38}$ The inclusion of $\mathrm{NO}_{2}$-BPCAs fractions would greatly assist in constructing a more robust regional and global $\mathrm{DBC}$ and $\mathrm{BC}$ budgets.

\section{MATERIALS AND METHODS}

2.1. Seawater Collection and Preparation. The stratified (i.e., surface, middle, and bottom) seawater samples were collected from 113 sites in summer (August 11 to September 6) and 44 sites in winter (18-26 December) in 2014. The summertime sites covered the whole BS, and the wintertime sites located only within the central and eastern BS (Figure 1b). Upon retrieval of the seawater samples from Niskin bottles, they were immediately filtered through $47 \mathrm{~mm}$ diameter precombusted $\left(450{ }^{\circ} \mathrm{C}, 4 \mathrm{~h}\right)$ quartz fiber filters (Whatman, a nominal pore size of $0.7 \mu \mathrm{m}$ ) on board to implement the separation between the particulate and dissolved phases. The particulate phase was reweighed under the same conditions as those for the blank filters and stored at $-20{ }^{\circ} \mathrm{C}$ for the PBC determination. The mass concentrations of the total suspended solids (TSS, $\mathrm{mg} \mathrm{L}^{-1}$ ) were calculated by dividing the dry weight of solids onto the filter by the total filtered seawater volume. For the dissolved phase, an aliquot of $1 \mathrm{~L}$ was cautiously acidified with concentrated $\mathrm{HCl}$ (32\%, analytical grade) to $\mathrm{pH} 2$. The acidified filtrate was extracted for the DBC using the HPLC grade $\mathrm{MeOH}$ prerinsed solidphase extraction (SPE) cartridges (Supelco Supelclean ENVIChrom $\mathrm{P}, 500 \mathrm{mg}$ ) at a flow rate of less than $5 \mathrm{~mL} \mathrm{~min}{ }^{-1}$. Following the extraction procedure, the SPE cartridges were desalted with $20 \mathrm{~mL}$ of $\mathrm{HCl}$ with $\mathrm{pH} 2$, dried under an airstream, and stored at $-20{ }^{\circ} \mathrm{C}$ for subsequent $\mathrm{DBC}$ quantification.

2.2. PBC Measurement. The analytical procedures for the bulk particulate OC (POC) and dissolved OC (DOC) are detailed in Text S1. The TSS was measured for the PBC on a Desert Research Institute (DRI) Model 2001 Thermal/Optical Carbon Analyzer using the Interagency Monitoring of Protected Visual Environment (IMPROVE) protocol. ${ }^{2,15,39-42}$ Prior to the instrumental analysis, the TSS was acidified with $\mathrm{HCl}$ fumes (32\%) for at least $24 \mathrm{~h}$ to completely eliminate the inorganic carbon. The inorganic carbon-free TSS was first heated in a pure $\mathrm{He}$ atmosphere. Then, the atmosphere was switched to a mixture of $2 \% \mathrm{O}_{2} / 98 \% \mathrm{He}$. Accordingly, three $\mathrm{BC}$ subfractions $(\mathrm{BC} 1, \mathrm{BC} 2$, and $\mathrm{BC} 3)$ were generated at three temperature stages $\left(580,740\right.$, and $\left.840{ }^{\circ} \mathrm{C}\right)$. During the pure $\mathrm{He}$ environment, pyrolysis of organic carbon $\left(\mathrm{OCP}_{\mathrm{yro}}\right)$ occurred and was monitored by the reflectance laser. The quantity of $\mathrm{OCP}_{\text {yro }}$ is defined as the carbon that evolves in the oxidizing atmosphere until the reflectance laser signal returns to its initial value. ${ }^{43,44}$ The protocol calculated $\mathrm{PBC}$ as the sum of three $\mathrm{BC}$ subfractions minus the $\mathrm{OCP}_{\text {yro }}$. The relative standard deviation (RSD) for $\mathrm{PBC}$ analysis averaged $<5 \%$ for duplicates.

2.3. DBC Measurement. The DBC was measured using the BPCAs molecular marker method developed in our laboratory, which was described in detail in Text S2. In brief, the $\mathrm{DBC}$ was eluted with $10 \mathrm{~mL}$ of $\mathrm{MeOH}$ from the SPE cartridges. The eluates were concentrated to $\sim 0.5 \mathrm{~mL}$ with a high-purity $\mathrm{N}_{2}$ stream and then transferred into $2 \mathrm{~mL}$ Teflon digestion tubes. After the eluates were evaporated to dryness, $0.5 \mathrm{~mL}$ of $65 \% \mathrm{HNO}_{3}$ was added. The tubes were sealed and heated at $170{ }^{\circ} \mathrm{C}$ for $7 \mathrm{~h}$. After the tubes cooled, the remaining $\mathrm{HNO}_{3}$ and water were evaporated under a high-purity $\mathrm{N}_{2}$ stream. Subsequently, $5 \mu \mathrm{L}$ of biphenyl-2'2-dicarboxylic acid $\left(2 \mu \mathrm{g} \mu \mathrm{L}^{-1}\right.$ in $\left.\mathrm{MeOH}\right)$ was added as an internal standard. The samples were redissolved in $1 \mathrm{~mL}$ of $\mathrm{MeOH} /$ water mixture (v/ $\mathrm{v}, 50: 50)$ and then transferred into autosampler vials for BPCAs analysis.

We used the LCQ Fleet Ion Trap HPLC-MS systems (Thermo Scientific) to seek the optimal separation conditions (Table S1) and identify the BPCAs target compounds (Table S2). We then applied the same chromatographic settings to the Waters Alliance E2695 HPLC system (outfitted with a photodiode array ultraviolet absorbance detector and an 
autosampler) to quantify the BPCAs in seawater samples. In this study, a total of 14 BPCAs (including seven $\mathrm{NO}_{2}$-BPCAs) with the $-\mathrm{COOH}$ numbers $\geq 3$ were defined as $\mathrm{DBC}$ molecular markers (Table S2). To establish the conversion factor between the total BPCAs-C (tBPCAs- $\mathrm{C}$, the carbon in all quantified BPCAs) and DBC, seven BC reference materials, including the two commercially purchased charcoals (charcoal \#1 and \#2), three self-collected and then purified soot materials (bus, tricycle, and ship), and two high-molecularweight $\mathrm{PAH}$ model substances (perylene and coronene) (Table S3), which covered the whole BC combustion continuum, were systematically analyzed. The RSD for DBC analysis was on average $<5 \%$ for duplicates.

\section{RESULTS}

3.1. Carbon Yields and BPCAs Distributions in Tested BC Reference Materials. For the seven oxidized BC reference materials, we calculated the carbon yields through the $\mathrm{tBPCAs-C}$ divided by the initial BC content. For charcoals and PAHs, we assume all carbon in them is BC; and for other collected soot materials, the remaining carbon following thermal purification treatment is regarded as BC, which is quantified by elemental analysis. The carbon yields and BPCAs distributions of these tested $\mathrm{BC}$ reference materials are illustrated in Figure 2 and Table S3. The average carbon

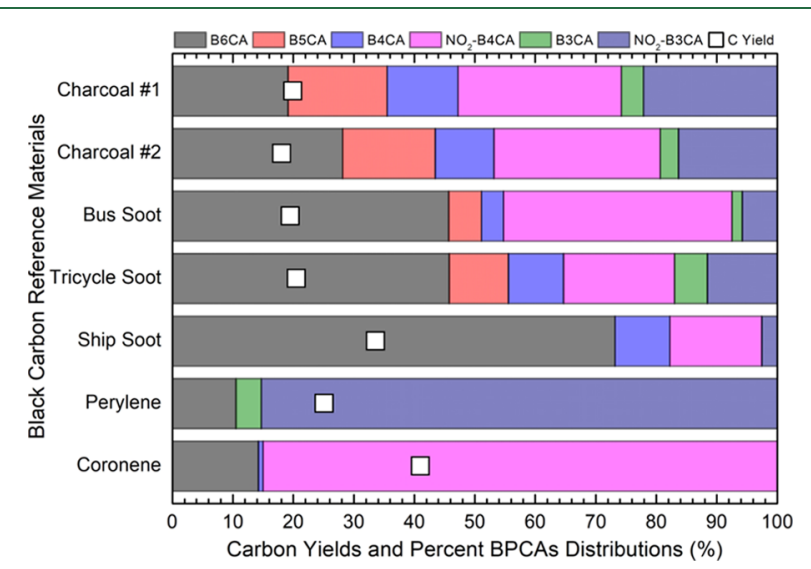

Figure 2. Carbon yields and BPCAs distributions of the seven oxidized black carbon reference materials. Note: details on these black carbon reference materials are referenced from the captions in Table S3.

yield was $25.4 \pm 8.7 \%$, with the individual carbon yields varying by a factor of $>2$, ranging from $18.1 \%$ for charcoal \#2 to $41.0 \%$ for $\mathrm{PAH}$ coronene. Here, we used the average conversion factor of 4.0 (the inverse of the averaged carbon yield) to convert the tBPCAs-C into DBC for our coastal seawater samples $([\mathrm{DBC}]=4.0 \times[\mathrm{tBPCAs}-\mathrm{C}])$.

The two commercially purchased charcoals have similar carbon yields (19.9 and 18.1\%), but with different BPCAs distributions. Charcoal \#1 is characterized by lower B6CA but higher $\mathrm{B} 3 \mathrm{CA}$ and $\mathrm{NO}_{2}-\mathrm{B} 3 \mathrm{CA}$ than charcoal \#2. For soot, the ship soot showed distinct carbon yield and BPCAs distributions from those of bus soot and tricycle soot, with the former having much higher carbon yield (33.6\%) and B6CA (73.2\%). For PAHs, the carbon yield of the five-ring perylene is $25.1 \%$, while that of the seven-ring coronene is much higher (41.0\%). The exclusive production of B6CA and B3CA (including $\mathrm{NO}_{2}$-B3CA) from perylene and $\mathrm{B} 6 \mathrm{CA}$ and
B4CA (including $\mathrm{NO}_{2}$-B4CA) from coronene matches well with earlier results reported by Ziolkowski et al., ${ }^{33}$ who also included $\mathrm{NO}_{2}$-BPCAs but with the GC-MS method. In addition, the relative BPCAs distributions of these two highmolecular-weight $\mathrm{PAH}$ substances are consistent with the theoretical values calculated from their stoichiometry. The results obtained from the various BC reference materials covering the whole $\mathrm{BC}$ combustion spectrum clearly demonstrated that $\mathrm{NO}_{2}$-BPCAs constituted a significant fraction of tBPCAs $\left(\mathrm{NO}_{2}\right.$-BPCAs $/ \mathrm{tBPCAs}=17.8-85.3 \%$; Table S3), implying that our determination and inclusion of $\mathrm{NO}_{2}$-BPCAs will to a large extent promote the accuracy of environmental DBC measurements. This will further refine a more robust regional and global DBC cycling and budgets, like updating the magnitudes of the current global atmospheric and riverine DBC fluxes and oceanic DBC pools in this study (see Section 4.4).

3.2. Spatiotemporal Variations of Coastal PBC and DBC. A major problem in quantifying $\mathrm{BC}$ is due to its physiochemical complexity as a combustion continuum, which results in diverse $\mathrm{BC}$ methodological developments from different disciplines for specific scientific questions. ${ }^{7-9,13}$ The TOR method for PBC here has been tested by Han et al., ${ }^{43,44}$ who demonstrated that it can effectively determine the entire BC continuum, including the relatively labile charcoal and highly aromatic soot condensates. ${ }^{40-42}$ The BPCAs method for the DBC detects a window of the aromatic moieties with varying degrees of polycondensation. ${ }^{33,38}$ The shortage of the TOR-based measurements on the seven examined BC reference materials limited our direct comparisons between these two methods. Despite this absence, an integrated intermethod comparison conducted by Ziolkowski et al. ${ }^{33}$ revealed that the inclusion of $\mathrm{NO}_{2}$-BPCAs into tBPCAs yielded comparable (RSD < 16\%) BC concentrations for wood/grass char and hexane soot reference materials with those obtained with the TOR method. ${ }^{7}$ This implied that, to a large extent, the direct comparisons between the TOR-based PBC and BPCAs-based DBC measured in this study are believable.

For $\mathrm{PBC}$, in summer, there were no apparent vertical variations (Figure $3 \mathrm{a}-\mathrm{c}$ ). The $\mathrm{PBC}$ averages in surface, middle, and bottom were $11.6 \pm 8.6,12.0 \pm 8.2$, and $13.4 \pm 9.2 \mu \mathrm{g}$ $\mathrm{L}^{-1}$, respectively (Table S4). Also, there were no obvious horizontal variations. In winter, however, the $\mathrm{PBC}$ values increased drastically ( $t$ test, $p<0.001$ ), with all layer-averages augmenting by factors of $\sim 4$ (Table S4). The PBC averages in surface, middle, and bottom were $39.1 \pm 36.8,44.1 \pm 39.7$, and $53.1 \pm 46.1 \mu \mathrm{g} \mathrm{L}^{-1}$, respectively. Meanwhile, the vertical variations became very evident (Figure $3 \mathrm{~d}-\mathrm{f}$ ), following an increasing pattern of surface $<$ middle $<$ bottom, which was particularly true in southern Bohai Strait. For instance, the PBC in the southernmost site increased from $144.3 \mu \mathrm{g} \mathrm{L}^{-1}$ for the surface, to $175.2 \mu \mathrm{g} \mathrm{L}^{-1}$ for the middle, and to $206.1 \mu \mathrm{g} \mathrm{L}^{-1}$ for the bottom, whereas it stayed relatively constant in the northernmost site $\left(13.5-15.9 \mu \mathrm{g} \mathrm{L}^{-1}\right)$ (Table S5). Horizontally, significantly higher values (nearly 1 order of magnitude; $t$ test, $p<0.001)$ occurred in southern $(85.6 \pm 58.7,107.9 \pm$ 67.3 , and $\left.128.7 \pm 77.4 \mu \mathrm{g} \mathrm{L}^{-1}\right)$ than those in northern Bohai Strait $\left(10.4 \pm 3.1,11.3 \pm 2.8\right.$, and $13.9 \pm 2.0 \mu \mathrm{g} \mathrm{L}^{-1}$ in the surface, middle, and bottom, respectively; Table S5). The spatiotemporal variations of TSS and POC (Figures S1 and $\mathrm{S} 2$ ) are consistent with those of $\mathrm{PBC}$, as also reflected from the 

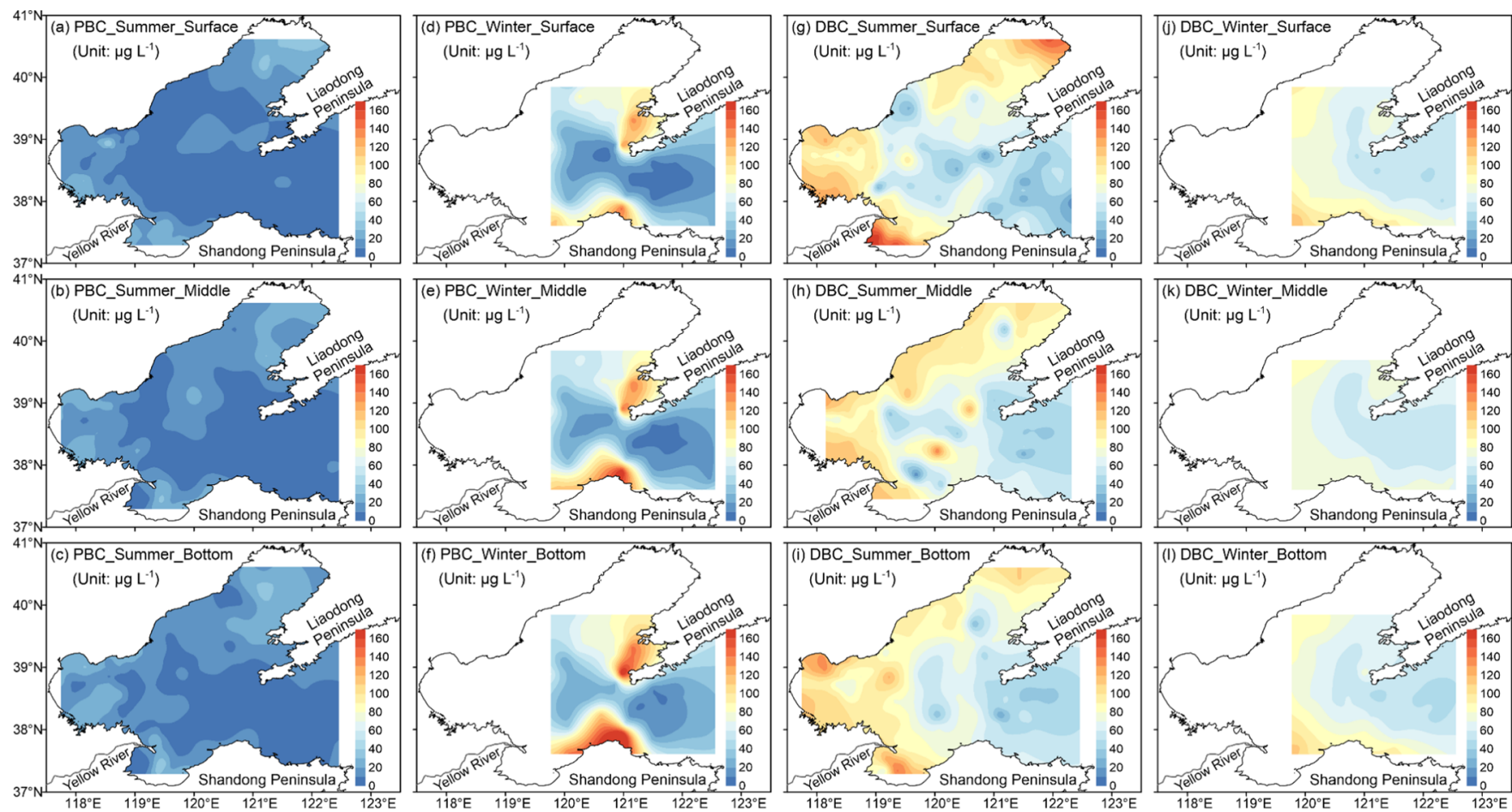

Figure 3. Spatiotemporal variations of $\mathrm{PBC}$ and DBC concentrations in coastal BS and NYS.

significant positive correlations between themselves (Figures S3 and S4).

Similar to PBC, DBC in summer also exhibit no apparent vertical variations (Figure $3 \mathrm{~g}-\mathrm{i}$ ). The DBC averages in surface, middle, and bottom were $80.8 \pm 30.5,75.5 \pm 25.8$, and $80.0 \pm$ $25.2 \mu \mathrm{g} \mathrm{L}^{-1}$, respectively (Table S4). Horizontally, in contrast to the uniform distributions of $\mathrm{PBC}, \mathrm{DBC}$ in the surface, middle, and bottom all decreased seaward markedly ( $t$ test, $p<$ $0.001)$, with highest $(102.0 \pm 22.5,92.7 \pm 15.2$, and $98.8 \pm$ $16.7 \mu \mathrm{g} \mathrm{L}^{-1}$ ) occurring in the river-influenced near-shore areas but lowest $\left(35.7 \pm 16.4,42.3 \pm 9.9\right.$, and $\left.46.3 \pm 6.1 \mu \mathrm{g} \mathrm{L}^{-1}\right)$ in the central NYS (Table S5). In winter, however, in contrast to the gradually elevated PBC from the surface to the bottom, there were no obvious vertical variations for the $\mathrm{DBC}$ (Figure $3 \mathrm{j}-1)$. The DBC averages in surface, middle, and bottom were $67.8 \pm 15.7,61.4 \pm 10.0$, and $66.1 \pm 15.3 \mu \mathrm{g} \mathrm{L}^{-1}$, respectively (Table S4). The horizontal variations of the DBC in winter largely resembled those of $\mathrm{PBC}$, with significantly elevated values in southern $(82.8 \pm 6.7,75.5 \pm 5.8$, and $79.8 \pm 2.5 \mu \mathrm{g}$ $\left.\mathrm{L}^{-1}\right)$ than those in northern Bohai Strait $(50.4 \pm 0.6,53.5 \pm$ 2.8 , and $50.7 \pm 5.3 \mu \mathrm{g} \mathrm{L}^{-1}$ in the surface, middle, and bottom, respectively; Table S5). Moreover, consistent with that in summer, the DBC in winter also showed a seaward decreasing trend (DBC in surface, middle, and bottom in central NYS were as low as $53.5 \pm 4.3,53.4 \pm 1.2$, and $51.2 \pm 4.5 \mu \mathrm{g} \mathrm{L}^{-1}$, respectively; Table S5). The spatiotemporal variations of DOC (Figure S5) differed significantly from those of the DBC, and there was no correlation between them $\left(R^{2}<0.07, p>0.05\right.$; Figure S6).

3.3. BPCAs Distributions along River-to-Ocean Continuum. The averaged BPCAs distributions in the coastal BS and NYS were similar, irrespective of the sampling periods and layers (Figure 4a). B5CA and B6CA, which are indicative of a structurally high aromatic and thus condensed DBC, constituted $22-24 \%$ of tBPCAs (Table S6). In comparison, the upstream riverine $\mathrm{DBC}$ in Bohai Rim contained higher
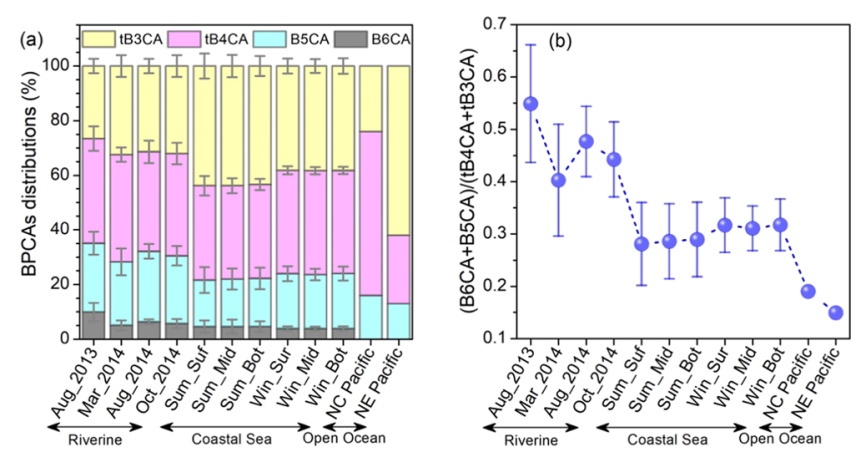

Figure 4. Comparisons of BPCAs distributions along the river-toocean continuum. Note: (a) tB3CA (tB4CA) is the sum of B3CA (B4CA) and $\mathrm{NO}_{2}$-B3CA $\left(\mathrm{NO}_{2}-\mathrm{B} 4 \mathrm{CA}\right)$. (b) BPCAs data for the riverine and open ocean are referenced from Fang et al. ${ }^{2}$ and Ziolkowski and Druffel, ${ }^{31}$ respectively, both of which quantified the $\mathrm{NO}_{2}$-BPCAs.

quantities of B5CA and B6CA (28-35\%), ${ }^{2}$ while the DBC from the downstream open Pacific Ocean were B6CAdepleted, with (B5CA + B6CA) less than $15 \% .{ }^{31}$ The degree of $\mathrm{DBC}$ aromatic condensation based on the ratio of (B6CA + $\mathrm{B} 5 \mathrm{CA}) /(\mathrm{tB} 4 \mathrm{CA}+\mathrm{tB} 3 \mathrm{CA})$ decreased significantly ( $t$ test, $p<$ $0.01)$ and continuously from rivers $(0.40-0.55)$, to the coastal seas $(0.28-0.32)$, and then to the remote open ocean $(0.15-$ 0.18) (Figure 4b).

3.4. Comparisons of the DBC Concentrations from Three Different Methods. We compared the riverine and coastal sea DBC concentrations calculated from three different methods developed from this study (Text S2), Dittmar, ${ }^{34}$ and Stubbins et al. $^{45}$ (Text S3). Of which, the latter two were widely used in the DBC concentration calculations. ${ }^{9,35,38,46-50}$ The DBC calculated by the method developed in the present study correlated significantly $\left(R^{2} \geq 0.88, p<0.01\right)$ with those from both Dittmar ${ }^{34}$ and Stubbins et al. ${ }^{45}$ (Figure 5). Notably, 
however, the former was 2.3-3.0 times higher than those from the latter two methods.
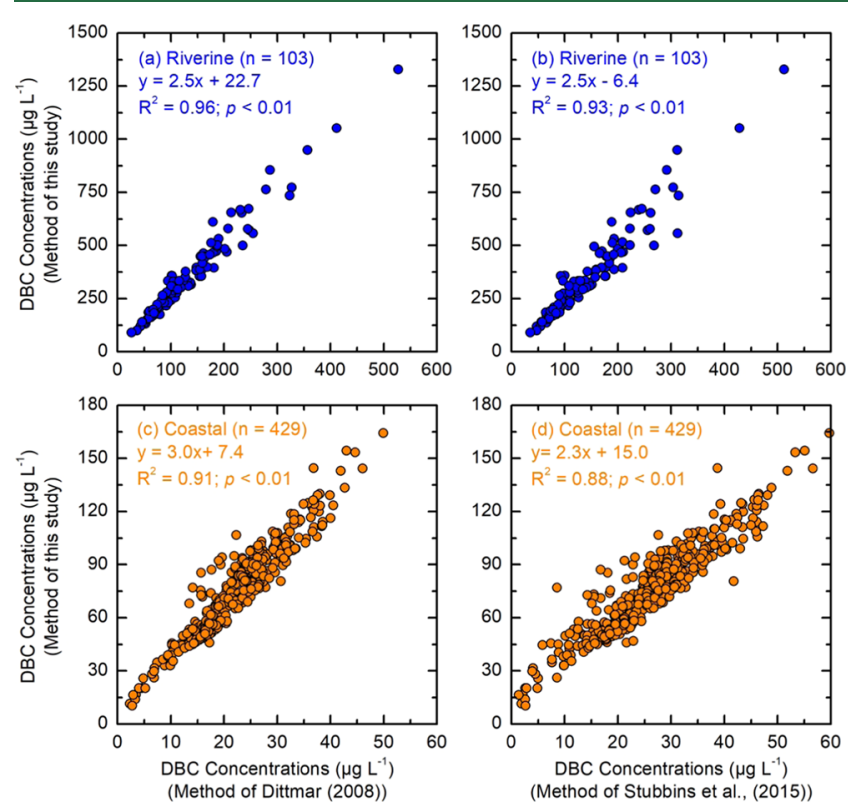

Figure 5. Comparisons of riverine and coastal sea DBC concentrations calculated from three different methods. Note: (a) these methods were developed in the present study, Dittmar, ${ }^{34}$ and Stubbins et al., ${ }^{45}$ respectively (Text S3). (b) Riverine data are referenced from Fang et al. ${ }^{2}$

\section{DISCUSSION}

4.1. Dynamics of Coastal PBC. As a typical shelf marginal sea, the BS is strongly influenced by river inputs. The Yellow River (Figure 1b), ranking as the world's second-largest river in terms of sediment loads and representing $\sim 6 \%$ of the global river sediment flux into the ocean, ${ }^{51}$ flows directly into the BS. The sediment discharge from the Yellow River has distinct seasonal variability. ${ }^{52}$ It is estimated that over $80 \%$ of the annual Yellow River sediment release into the BS occurs in summer. ${ }^{53}$ During this period, the BS water column exhibits high stratification and vertical mixing is thus remarkably weakened (Figure S7). Such hydrodynamic processes result in the quick deposition of the river-derived sediments within the river mouth $(<30 \mathrm{~km})$, even at the timing of the summer "Water and Sediment Regulation Project", a short duration ( $\sim 20$ days) in which $30-50 \%$ of the annual Yellow River sediments are discharged into the BS. ${ }^{53-55}$ Therefore, the TSS and associated PBC and POC in BS were of low levels in summer, and they also had no obvious horizontal or vertical variations (Figures $3 a-c, S 1 a-c$, and $\mathrm{S} 2 \mathrm{a}-\mathrm{c}$ ).

In winter, however, the BS is strongly affected by the prevailing northerly and/or northwesterly East-Asian monsoon. ${ }^{2,53}$ This strong wind produces waves up to $7 \mathrm{~m}$ that transmit toward the coast of the Yellow River delta, resulting in the intensive resuspension of the estuarine seabed sediments off the Yellow River delta due to the elevated bottom shear stress. ${ }^{53,56,57}$ Moreover, the intense vertical mixing (Figure S7) maintains the sediments at a state of resuspension, facilitating their long-range waterborne transport and subsequent export. ${ }^{53,57}$ Driven by the monsoon-induced Shandong Coastal Current (SCC) (Figure $1 \mathrm{~b}$ ), ${ }^{58,59}$ the sediments are readily mobilized southward to the Laizhou Bay and then transported eastward along the coast of the Shandong Peninsula to NYS through the southern Bohai Strait. Therefore, higher levels of particulates were measured in winter in comparison with those in summer (Table S4), and horizontally higher TSS, PBC, and POC occurred in southern than in northern Bohai Strait (Figures $3 \mathrm{~d}-\mathrm{f}, \mathrm{S} 1 \mathrm{~d}-\mathrm{f}$, and $\mathrm{S} 2 \mathrm{~d}-\mathrm{f}$ ). The significant positive correlations between these particulate phases $\left(R^{2}=0.73-0.91\right.$, $p<0.01$; Figures S3 and S4) suggested the coupled mechanisms controlling their dynamics. To conclude, the integrated influences of the strong winter northerly and/or northwesterly monsoon-induced sediment resuspension process and coastal current transport largely regulate the sources and dynamics of TSS and associated PBC and POC in coastal BS in winter. In addition, these factors were found to exert a crucial influence on the sorting of sedimentary BC with different physical properties in this region. ${ }^{60}$ Within $\sim 30 \mathrm{~km}$ of the Yellow River estuary, BC with larger particle size from biomass burning decreased from 90 to $20 \%$, and the smaller fossil fuel combustion-derived BC increased from 10 to $80 \%$. Beyond $\sim 30 \mathrm{~km}$, the relative proportions of these two types of BC changed slightly.

4.2. Dynamics of the Coastal DBC. Our nearly simultaneous investigations in 2014 have found that the river DBC in Bohai Rim averaged $346 \pm 157 \mu \mathrm{g} \mathrm{L}^{-1}$ in summer and $229 \pm 90 \mu \mathrm{g} \mathrm{L}^{-1}$ in winter, ${ }^{2}$ both of which were $\sim 4$ times higher than the averages measured in the adjacent coastal China seas $\left(\sim 80\right.$ and $\sim 60 \mu \mathrm{g} \mathrm{L}^{-1}$ in summer and winter, respectively; Figure S8). Such steep river-to-sea concentration gradients, in combination with the significant negative correlations between the DBC concentrations and salinity in this study $\left(R^{2}=0.18-0.86, p<0.01\right.$; Figure S9) and also in our previous work ${ }^{29}$ conducted in the same region but from different sampling periods, point toward river runoff as the major source of the DBC to the coastal seas. This judgment can further be testified by our preliminary constrained DBC budget, in which we calculated that riverine discharge and atmospheric deposition each delivered $6-16$ and $\sim 0.9 \mathrm{Gg} \mathrm{yr}^{-1}$ of DBC to $\mathrm{BS}^{2}$ The contribution of the DBC into BS from riverine inputs was approximately 1 order of magnitude higher than that from atmospheric delivery. From a global perspective, the available DBC fluxes into the ocean from rivers and atmospheric deposition are at $26.5 \pm 1.8$ and $1.8 \pm 0.8 \mathrm{Tg}$ $\mathrm{yr}^{-1}$, respectively. ${ }^{35,47}$ Surprisingly, the relative proportions of riverine discharge and atmospheric deposition of the DBC into the BS corresponded well with the above global averages. This manifests that the coastal BS serves as an ideal regional template to study the global-scale DBC cycling.

When the overwhelmingly high levels of riverine $\mathrm{DBC}$ enter the estuaries, it can be automatically diffused seaward due to the significant differences between the river and coastal DBC concentrations. This diffusion mechanism mainly results in the observed distinct DBC decreasing seaward pattern (Figure $3 g-1)$. In addition to the inherent diffusion mechanism, the dissolving characteristic of DBC facilitates it to be transported and redistributed along with the hydrodynamic forcings, ${ }^{29}$ like the coastal currents. Driven by the eastward SCC (Figure 1b), the $\mathrm{DBC}$ can be readily mobilized from BS to NYS through the southern Bohai Strait. Because of no large rivers flowing directly into the NYS and the resultant higher DBC levels in BS compared with those in NYS (Figure $3 g-1$ ), the SCCdriven eastward transport largely regulates the horizontally spatial variations of DBC within the Bohai Strait. 
4.3. Significant and Continuous Decrease of the DBC Aromatic Condensation along River-to-Ocean Continuum Transport. If the DBC quality is conservatively mixed along with the river-to-ocean continuum transport, we would expect that the BPCAs molecular ratios in coastal BS and NYS remain relatively constant and also resemble those from the upstream rivers in Bohai Rim and downstream the open Pacific Ocean. However, this is not the case. The ratio of (B6CA + $\mathrm{B} 5 \mathrm{CA}) /(\mathrm{tB} 4 \mathrm{CA}+\mathrm{tB} 3 \mathrm{CA})$ decreased with increasing salinity in BS and NYS (Figures S10-S12). Most importantly, it decreased significantly and continuously from rivers to the coastal seas and then to the remote open ocean (Figure $3 b$ ). The spatially continuous alterations in the DBC quality evidently indicated the loss behavior of the DBC aromatic condensation during its transport along the river-to-ocean continuum.

The loss of the $\mathrm{DBC}$ aromatic condensation along the riverto-ocean continuum transport could in large part be due to their differing degrees of photochemical transformations. ${ }^{10,19,61,62}$ As aforementioned, river is the predominant source of DBC mobilization from the land to ocean, and the transport distances of the DBC reaching the rivers, coastal seas, and open ocean, therefore, increase stepwise. Accordingly, the durations of DBC exposure to solar radiation also increase gradually. The modeled sunlight irradiation experiment has uncovered that photodegradation preferentially removes the polycondensed aromatic structures (i.e., B6CA and B5CA), yielding a pool of $\mathrm{DBC}$ molecules that are less aromatic (i.e., $\mathrm{B} 3 \mathrm{CA}$ and $\mathrm{B} 4 \mathrm{CA}) .{ }^{19,20,62}$ As a result, the $\mathrm{DBC}$ in rivers receiving the least solar radiation was characterized by the largest aromatic condensation, exhibiting the highest (B6CA + $\mathrm{B} 5 \mathrm{CA}) /(\mathrm{tB} 4 \mathrm{CA}+\mathrm{tB} 3 \mathrm{CA})$ ratio. In comparison, however, the open oceanic $\mathrm{DBC}$, which was subjected to the longest sunlight exposure, was thus with the least aromaticity. The photochemical-induced molecular transformations of DBC have been also observed in the geographically wide-distributed regions, such as the western South China Sea, ${ }^{48}$ the Atlantic Ocean surface waters, ${ }^{63}$ and even the global-scale cryosphere. ${ }^{64}$ From a global perspective, the photodegradation process has been identified as a dominant global oceanic DBC sink, with an estimated flux of $20-490 \mathrm{Tg} \mathrm{yr}^{-1}$. ${ }^{19}$ Here, it is worth mentioning that, in addition to the above-proposed photooxidation pathway, the observed lower BPCAs molecular ratios in aerosols together with the comparable ranges of $\delta^{13} \mathrm{C}$ signatures between the aerosol BC and open oceanic DBC to some extent point toward aerosol deposition as another potential mechanism resulting in the less polycondensed open ocean DBC. ${ }^{10,47,65,66}$ Despite this recognition, estimating the relative contributions of these mechanisms remains an enormous challenge and is yet to be resolved.

4.4. Implications for Updating Global DBC Fluxes and Pools. The DBC concentrations used for estimating the global-scale DBC fluxes ${ }^{35,47}$ and oceanic pools ${ }^{63}$ were quantified by methods either from Dittmar ${ }^{34}$ or Stubbins et al. ${ }^{45}$ The DBC determined by these two methods was $2.3-3.0$ times lower than that determined by the method developed in the present study (Figure 5), implying that the existing estimates of the global DBC fluxes and pools were largely underestimated.

The significant linear correlations of the DBC concentrations calculated from the three different methods $\left(R^{2} \geq\right.$ $0.88, p<0.01$; Figure 5) make updating the current globalscale DBC fluxes and pools possible and reasonable.
Considering the original quantification and calculation methods, factors of 2.4 (average of 2.5 and 2.3; Figure 5b,d) and 2.5 (Figure 5a) were used for updating the global atmospheric $\left(1.8 \mathrm{Tg} \mathrm{yr}^{-1}\right.$ ) and riverine $\left(26.5 \mathrm{Tg} \mathrm{yr}^{-1}\right) \mathrm{DBC}$ fluxes, respectively, ${ }^{35,47}$ and 3.0 (Figure 5c) was used for updating the global oceanic DBC pool $(12 \mathrm{Gt}){ }^{63}$ Through these revisions, the global DBC fluxes into the ocean from the atmospheric and riverine delivery were estimated at rates of 4.3 and 66.3 $\mathrm{Tg} \mathrm{yr}^{-1}$, respectively, and the global oceanic DBC pool was approximately $36 \mathrm{Gt}$. The much higher values obtained resulted primarily from the inclusion of $\mathrm{NO}_{2}$-BPCAs fractions into tBPCAs. Regardless of the rivers or coastal seas, $\mathrm{NO}_{2}$-BPCAs correlated significantly with both non-nitrated BPCAs $\left(R^{2}=0.67-0.71, p<0.01\right)$ and tBPCAs $\left(R^{2}=0.87-\right.$ $0.91, p<0.01$ ) (Figure S13). The ratio of $\mathrm{NO}_{2}$-BPCAs/ tBPCAs was $\sim 34 \%$ in rivers and increased to $\sim 51 \%$ in coastal seas, emphasizing the importance and necessity of the determination and inclusion of the $\mathrm{NO}_{2}$-BPCAs into tBPCAs on future $\mathrm{DBC}$-associated studies. Despite the different $\mathrm{DBC}$ calculating methods adopted by different groups, the direct comparisons of their DBC concentrations are accessible if the individual BPCAs fraction concentrations are provided, like Table S6 in the present study. Only in this way can we facilitate future researchers reanalyzing and recomparing the literature-presented DBC data sets and eventually have a more refined understanding of the DBC geochemistry, such as the sources-to-sinks processes and fluxes. ${ }^{38}$

\section{ASSOCIATED CONTENT}

\section{Supporting Information}

The Supporting Information is available free of charge at https://pubs.acs.org/doi/10.1021/acs.est.0c06386.

Detailed analytical procedures for POC and DOC (Text S1); HPLC-MS BPCAs methodological development in our laboratory (Text S2); three different DBC concentration calculation methods (Text S3); the established chromatographic conditions of the mobile phase mixing gradients (Table S1); the retention time and selected monitoring ions of the BPCAs target compounds (Table S2); the carbon yields and percent BPCAs distributions of the seven analyzed BC reference materials (Table S3); detailed data on the measured geochemical parameters (Tables S4-S6); the spatiotemporal variations of the measured geochemical parameters (Figures S1, S2, S5, S7, S8, S10, and S11) and their correlations (Figures S3, S4, S6, S9, S12, and S13) (PDF)

\section{AUTHOR INFORMATION}

\section{Corresponding Authors}

Yingjun Chen - Shanghai Key Laboratory of Atmospheric Particle Pollution and Prevention (LAP3), Department of Environmental Science and Engineering, Fudan University, Shanghai 200438, China; Phone: +86-21-31248999; Email: yjchenfd@fudan.edu.cn

Tian Lin - College of Marine Ecology and Environment, Shanghai Ocean University, Shanghai 201306, China; (1) orcid.org/0000-0001-9813-7782; Phone: +86-2161908340; Email: tlin@shou.edu.cn 


\section{Authors}

Yin Fang - College of Marine Ecology and Environment, Shanghai Ocean University, Shanghai 201306, China; (1) orcid.org/0000-0002-8977-5552

Guopei Huang - State Key Laboratory of Environmental Geochemistry, Guiyang Institute of Geochemistry, Chinese Academy of Sciences, Guiyang 550081, China

Limin Hu - College of Marine Geosciences, Ocean University of China, Qingdao 266100, China

Chongguo Tian - Key Laboratory of Coastal Environmental Processes and Ecological Remediation, Yantai Institute of Coastal Zone Research, Chinese Academy of Sciences, Yantai 264003, China; (1) orcid.org/0000-0001-6058-9353

Jingqian Xie - College of Marine Ecology and Environment, Shanghai Ocean University, Shanghai 201306, China

Jun Lin - College of Marine Ecology and Environment, Shanghai Ocean University, Shanghai 201306, China

Complete contact information is available at:

https://pubs.acs.org/10.1021/acs.est.0c06386

\section{Notes}

The authors declare no competing financial interest.

\section{ACKNOWLEDGMENTS}

This work was financially supported by the National Natural Scientific Foundation of China (No. 41703087) and the Foundation of Key Laboratory of Yangtze River Water Environment of Ministry of Education in Tongji University (Nos. YRWEF201802 and YRWEF201902). The authors wish to thank the crew of R/V Xiang Yang Hong 2 and 8, and Hao Hai for collecting the seawater samples.

\section{REFERENCES}

(1) Bauer, J. E.; Cai, W. J.; Raymond, P. A.; Bianchi, T. S.; Hopkinson, C. S.; Regnier, P. A. G. The changing carbon cycle of the coastal ocean. Nature 2013, 504, 61-70.

(2) Fang, Y.; Chen, Y.; Tian, C.; Wang, X.; Lin, T.; Hu, L.; Li, J.; Zhang, G.; Luo, Y. Cycling and Budgets of Organic and Black Carbon in Coastal Bohai Sea, China: Impacts of Natural and Anthropogenic Perturbations. Global Biogeochem. Cycles 2018, 32, 971-986.

(3) Jiao, N.; Liang, Y.; Zhang, Y.; Liu, J.; Zhang, Y.; Zhang, R.; Zhao, M.; Dai, M.; Zhai, W.; Gao, K.; Song, J.; Yuan, D.; Li, C.; Lin, G.; Huang, X.; Yan, H.; Hu, L.; Zhang, Z.; Wang, L.; Cao, C.; Luo, Y.; Luo, T.; Wang, N.; Dang, H.; Wang, D.; Zhang, S. Carbon pools and fluxes in the China Seas and adjacent oceans. Sci. China Earth Sci. 2018, 61, 1535-1563.

(4) Dai, M.; Yin, Z.; Meng, F.; Liu, Q.; Cai, W. J. Spatial distribution of riverine DOC inputs to the ocean: an updated global synthesis. Curr. Opin. Environ. Sustainability 2012, 4, 170-178.

(5) Coppola, A. I.; Druffel, E. R. M. Cycling of black carbon in the ocean. Geophys. Res. Lett. 2016, 43, 4477-4482.

(6) Coppola, A. I.; Seidel, M.; Ward, N. D.; Viviroli, D.; Nascimento, G. S.; Haghipour, N.; Revels, B. N.; Abiven, S.; Jones, M. W.; Richey, J. E.; Eglinton, T. I.; Dittmar, T.; Schmidt, M. W. I. Marked isotopic variability within and between the Amazon River and marine dissolved black carbon pools. Nat. Commun. 2019, 10, No. 4018.

(7) Hammes, K.; Schmidt, M. W. I.; Smernik, R. J.; Currie, L. A.; Ball, W. P.; Nguyen, T. H.; Louchouarn, P.; Houel, S.; Gustafsson, Ö.; Elmquist, M.; Cornelissen, G.; Skjemstad, J. O.; Masiello, C. A.; Song, J.; Peng, P. A.; Mitra, S.; Dunn, J. C.; Hatcher, P. G.; Hockaday, W. C.; Smith, D. M.; Hartkopf-Fröder, C.; Böhmer, A.; Lüer, B.; Huebert, B. J.; Amelung, W.; Brodowski, S.; Huang, L.; Zhang, W.; Gschwend, P. M.; Flores-Cervantes, D. X.; Largeau, C.; Rouzaud, J.-N.; Rumpel, C.; Guggenberger, G.; Kaiser, K.; Rodionov, A.; Gonzalez-Vila, F. J.; Gonzalez-Perez, J. A.; de la Rosa, J. M.; Manning, D. A. C.; López-
Capél, E.; Ding, L. Comparison of quantification methods to measure fire-derived (black/elemental) carbon in soils and sediments using reference materials from soil, water, sediment and the atmosphere. Global Biogeochem. Cycles 2007, 21, No. GB3016.

(8) Masiello, C. A. New directions in black carbon organic geochemistry. Mar. Chem. 2004, 92, 201-213.

(9) Wagner, S.; Jaffé, R.; Stubbins, A. Dissolved black carbon in aquatic ecosystems. Limnol. Oceanogr. Lett. 2018, 3, 168-185.

(10) Wagner, S.; Brandes, J.; Spencer, R. G. M.; Ma, K.; Rosengard, S. Z.; Moura, J. M. S.; Stubbins, A. Isotopic composition of oceanic dissolved black carbon reveals non-riverine source. Nat. Commun. 2019, 10, No. 5064.

(11) Myers-Pigg, A. N.; Louchouarn, P.; Amon, R. M. W.; Prokushkin, A.; Pierce, K.; Rubtsov, A. Labile pyrogenic dissolved organic carbon in major Siberian Arctic rivers: Implications for wildfire-stream metabolic linkages. Geophys. Res. Lett. 2015, 42, 377385.

(12) Wang, R.; Tao, S.; Wang, W.; Liu, J.; Shen, H.; Shen, G.; Wang, B.; Liu, X.; Li, W.; Huang, Y.; et al. Black Carbon Emissions in China from 1949 to 2050. Environ. Sci. Technol. 2012, 46, 7595-7603.

(13) Fang, Y.; Chen, Y.; Tian, C.; Lin, T.; Hu, L.; Huang, G.; Tang, J.; Li, J.; Zhang, G. Flux and budget of BC in the continental shelf seas adjacent to Chinese high BC emission source regions. Global Biogeochem. Cycles 2015, 29, 957-972.

(14) Wang, R.; Tao, S.; Balkanski, Y.; Ciais, P.; Boucher, O.; Liu, J.; Piao, S.; Shen, H.; Vuolo, M. R.; Valari, M.; Chen, H.; Chen, Y.; Cozic, A.; Huang, Y.; Li, B.; Li, W.; Shen, G.; Wang, B.; Zhang, Y. Exposure to ambient black carbon derived from a unique inventory and high-resolution model. Proc. Natl. Acad. Sci. U.S.A. 2014, 111, 2459-2463.

(15) Fang, Y.; Chen, Y.; Lin, T.; Hu, L.; Tian, C.; Luo, Y.; Yang, X.; Li, J.; Zhang, G. Spatiotemporal Trends of Elemental Carbon and Char/Soot Ratios in Five Sediment Cores from Eastern China Marginal Seas: Indicators of Anthropogenic Activities and Transport Patterns. Environ. Sci. Technol. 2018, 52, 9704-9712.

(16) Decesari, S.; Facchini, M. C.; Matta, E.; Mircea, M.; Fuzzi, S.; Chughtai, A. R.; Smith, D. M. Water soluble organic compounds formed by oxidation of soot. Atmos. Environ. 2002, 36, 1827-1832.

(17) Hockaday, W. C.; Grannas, A. M.; Kim, S.; Hatcher, P. G. Direct molecular evidence for the degradation and mobility of black carbon in soils from ultrahigh-resolution mass spectral analysis of dissolved organic matter from a fire-impacted forest soil. Org. Geochem. 2006, 37, 501-510.

(18) Zimmerman, A. R. Abiotic and microbial oxidation of laboratory-produced black carbon (biochar). Environ. Sci. Technol. 2010, 44, 1295-1301.

(19) Stubbins, A.; Niggemann, J.; Dittmar, T. Photo-lability of deep ocean dissolved black carbon. Biogeosciences 2012, 9, 1661-1670.

(20) Wagner, S.; Jaffe, R. Effect of photodegradation on molecular size distribution and quality of dissolved black carbon. Org. Geochem. 2015, 86, 1-4.

(21) Li, M.; Bao, F.; Zhang, Y.; Sheng, H.; Chen, C.; Zhao, J. Photochemical Aging of Soot in the Aqueous Phase: Release of Dissolved Black Carbon and the Formation of O-1(2). Environ. Sci. Technol. 2019, 53, 12311-12319.

(22) Qi, Y.; Fu, W.; Tian, J.; Luo, C.; Shan, S.; Sun, S.; Ren, P.; Zhang, H.; Liu, J.; Zhang, X.; Wang, X. Dissolved black carbon is not likely a significant refractory organic carbon pool in rivers and oceans. Nat. Commun. 2020, 11, No. 5051.

(23) Alan Roebuck, J.; Podgorksi, D. C.; Wagner, S.; Jaffé, R. Photodissolution of charcoal and fire-impacted soil as a potential source of dissolved black carbon in aquatic environments. Org. Geochem. 2017, 112, 16-21.

(24) Andersson, A.; Deng, J.; Du, K.; Zheng, M.; Yan, C.; Skold, M.; Gustafsson, Ö. Regionally-varying combustion sources of the January 2013 severe haze events over Eastern China. Environ. Sci. Technol. 2015, 49, 2038-2043. 
(25) Wang, X.; Xu, C.; Druffel, E. R. M.; Xue, Y.; Qi, Y. Two black carbon pools transported by the Changjiang and Huanghe Rivers in China. Global Biogeochem. Cycles 2016, 30, 1778-1790.

(26) Chen, B.; Andersson, A.; Lee, M.; Kirillova, E. N.; Xiao, Q.; Krusa, M.; Shi, M.; Hu, K.; Lu, Z.; Streets, D. G.; Du, K.; Gustafsson, O. Source Forensics of Black Carbon Aerosols from China. Environ. Sci. Technol. 2013, 47, 9102-9108.

(27) Xu, W.; Wang, F.; Li, J.; Tian, L.; Jiang, X.; Yang, J.; Chen, B. Historical variation in black carbon deposition and sources to Northern China sediments. Chemosphere 2017, 172, 242-248.

(28) Xu, C.; Xue, Y.; Qi, Y.; Wang, X. Quantities and Fluxes of Dissolved and Particulate Black Carbon in the Changiiang and Huanghe Rivers, China. Estuaries Coasts 2016, 39, 1617-1625.

(29) Huang, G.; Chen, Y.; Tian, C.; Tang, J.; Zhang, H.; Luo, Y.; Li, J.; Zhang, G. Spatial Distributions and Seasonal Variations of Dissolved Black Carbon in the Bohai Sea, China. J. Coastal Res. 2016, 74, 214-227.

(30) Mannino, A.; Harvey, H. R. Black carbon in estuarine and coastal ocean dissolved organic matter. Limnol. Oceanogr. 2004, 49, 735-740.

(31) Ziolkowski, L. A.; Druffel, E. R. M. Aged black carbon identified in marine dissolved organic carbon. Geophys. Res. Lett. 2010, 37, No. L16601.

(32) Marques, J. S. J.; Dittmar, T.; Niggemann, J.; Almeida, M. G.; Gomez-Saez, G. V.; Rezende, C. E. Dissolved Black Carbon in the Headwaters-to-Ocean Continuum of Paraiba Do Sul River, Brazil. Front. Earth Sci. 2017, 5, 1-12.

(33) Ziolkowski, L. A.; Chamberlin, A. R.; Greaves, J.; Druffel, E. R. M. Quantification of black carbon in marine systems using the benzene polycarboxylic acid method: a mechanistic and yield study. Limnol. Oceanogr.: Methods 2011, 9, 140-149.

(34) Dittmar, T. The molecular level determination of black carbon in marine dissolved organic matter. Org. Geochem. 2008, 39, 396-407. (35) Jaffé, R.; Ding, Y.; Niggemann, J.; Vähätalo, A. V.; Stubbins, A.; Spencer, R. G. M.; Campbell, J.; Dittmar, T. Global Charcoal Mobilization from Soils via Dissolution and Riverine Transport to the Oceans. Science 2013, 340, 345-347.

(36) Roebuck, J. A., Jr.; Medeiros, P. M.; Letourneau, M. L.; Jaffe, R. Hydrological Controls on the Seasonal Variability of Dissolved and Particulate Black Carbon in the Altamaha River, GA. J. Geophys. Res.: Biogeosci. 2018, 123, 3055-3071.

(37) Roebuck, J. A.; Seidel, M.; Dittmar, T.; Jaffe, R. Land Use Controls on the Spatial Variability of Dissolved Black Carbon in a Subtropical Watershed. Environ. Sci. Technol. 2018, 52, 8104-8114.

(38) Jones, M. W.; Coppola, A. I.; Santín, C.; Dittmar, T.; Jaffe, R.; Doerr, S. H.; Quine, T. A. Fires prime terrestrial organic carbon for riverine export to the global oceans. Nat. Commun. 2020, 11, No. 2791.

(39) Cong, Z.; Kang, S.; Gao, S.; Zhang, Y.; Li, Q.; Kawamura, K. Historical trends of atmospheric black carbon on Tibetan Plateau as reconstructed from a 150-year lake sediment record. Environ. Sci. Technol. 2013, 47, 2579-2586.

(40) Han, Y. M.; Cao, J. J.; Yan, B. Z.; Kenna, T. C.; Jin, Z. D.; Cheng, Y.; Chow, J. C.; An, Z. S. Comparison of Elemental Carbon in Lake Sediments Measured by Three Different Methods and 150-Year Pollution History in Eastern China. Environ. Sci. Technol. 2011, 45, 5287-5293.

(41) Han, Y. M.; Wei, C.; Bandowe, B. A. M.; Wilcke, W.; Cao, J. J.; Xu, B. Q.; Gao, S. P.; Tie, X. X.; Li, G. H.; Jin, Z. D.; An, Z. S. Elemental Carbon and Polycyclic Aromatic Compounds in a 150 -Year Sediment Core from Lake Qinghai, Tibetan Plateau, China: Influence of Regional and Local Sources and Transport Pathways. Environ. Sci. Technol. 2015, 49, 4176-4183.

(42) Han, Y.; An, Z.; Marlon, J. R.; Bradley, R. S.; Zhan, C.; Arimoto, R.; Sun, Y.; Zhou, W.; Wu, F.; Wang, Q.; Burr, G. S.; Cao, J. Asian inland wildfires driven by glacial-interglacial climate change. Proc. Natl. Acad. Sci. U.S.A. 2020, 117, 5184-5189.

(43) Han, Y. M.; Cao, J. J.; An, Z. S.; Chow, J. C.; Watson, J. G.; Jin, Z. D.; Fung, K.; Liu, S. X. Evaluation of the thermal/optical reflectance method for quantification of elemental carbon in sediments. Chemosphere 2007, 69, 526-533.

(44) Han, Y. M.; Cao, J. J.; Chow, J. C.; Watson, J. G.; An, Z. S.; Jin, Z. D.; Fung, K.; Liu, S. X. Evaluation of the thermal/optical reflectance method for discrimination between char- and soot-EC. Chemosphere 2007, 69, 569-574.

(45) Stubbins, A.; Spencer, R. G. M.; Mann, P. J.; Holmes, R. M.; McClelland, J. W.; Niggemann, J.; Dittmar, T. Utilizing colored dissolved organic matter to derive dissolved black carbon export by arctic rivers. Front. Earth Sci. 2015, 3, 63.

(46) Bao, H.; Niggemann, J.; Huang, D.; Dittmar, T.; Kao, S.-J. Different Responses of Dissolved Black Carbon and Dissolved Lignin to Seasonal Hydrological Changes and an Extreme Rain Event. J. Geophys. Res.: Biogeosci. 2019, 124, 479-493.

(47) Bao, H.; Niggemann, J.; Luo, L.; Dittmar, T.; Kao, S. Aerosols as a source of dissolved black carbon to the ocean. Nat. Commun. 2017, 8, No. 510.

(48) Fang, Z.; Yang, W.; Chen, M.; Ma, H. Source and Fate of Dissolved Black Carbon in the Western South China Sea During the Southwest Monsoon Prevailing Season. J. Geophys. Res.: Biogeosci. 2017, 122, 2817-2830.

(49) Dittmar, T.; Paeng, J.; Gihring, T. M.; Suryaputra, I.; Huettel, M. Discharge of dissolved black carbon from a fire-affected intertidal system. Limnol. Oceanogr. 2012, 57, 1171-1181.

(50) Dittmar, T.; de Rezende, C. E.; Manecki, M.; Niggemann, J.; Ovalle, A. R. C.; Stubbins, A.; Bernardes, M. C. Continuous flux of dissolved black carbon from a vanished tropical forest biome. Nat. Geosci. 2012, 5, 618-622.

(51) Wang, H.; Yang, Z.; Saito, Y.; Liu, J. P.; Sun, X.; Wang, Y. Stepwise decreases of the Huanghe (Yellow River) sediment load (1950-2005): Impacts of climate change and human activities. Global Planet. Change 2007, 57, 331-354.

(52) Wang, X.; Ma, H.; Li, R.; Song, Z.; Wu, J. Seasonal fluxes and source variation of organic carbon transported by two major Chinese Rivers: The Yellow River and Changjiang (Yangtze) River. Global Biogeochem. Cycles 2012, 26, No. GB2025.

(53) Bi, N.; Yang, Z.; Wang, H.; Fan, D.; Sun, X.; Lei, K. Seasonal variation of suspended-sediment transport through the southern Bohai Strait. Estuarine, Coastal Shelf Sci. 2011, 93, 239-247.

(54) Hu, B.; Li, J.; Bi, N.; Wang, H.; Wei, H.; Zhao, J.; Xie, L.; Zou, L.; Cui, R.; Li, S.; Liu, M.; Li, G. Effect of human-controlled hydrological regime on the source, transport, and flux of particulate organic carbon from the lower Huanghe (Yellow River). Earth Surf. Processes Landforms 2015, 40, 1029-1042.

(55) Yu, Y.; Shi, X.; Wang, H.; Yue, C.; Chen, S.; Liu, Y.; Hu, L.; Qiao, S. Effects of dams on water and sediment delivery to the sea by the Huanghe (Yellow River): The special role of Water-Sediment Modulation. Anthropocene 2013, 3, 72-82.

(56) Li, G.; Xue, X.; Liu, Y.; Wang, H.; Liao, H. Diagnostic experiments for transport mechanisms of suspended sediment discharged from the Yellow River in the Bohai Sea. J. Geogr. Sci. 2010, 20, 49-63.

(57) Yang, Z.; Ji, Y.; Bi, N.; Lei, K.; Wang, H. Sediment transport off the Huanghe (Yellow River) delta and in the adjacent Bohai Sea in winter and seasonal comparison. Estuarine, Coastal Shelf Sci. 2011, 93, $173-181$.

(58) Cheng, P.; Gao, S.; Bokuniewicz, H. Net sediment transport patterns over the Bohai Strait based on grain size trend analysis. Estuarine, Coastal Shelf Sci. 2004, 60, 203-212.

(59) Hu, L.; Lin, T.; Shi, X.; Yang, Z.; Wang, H.; Zhang, G.; Guo, Z. The role of shelf mud depositional process and large river inputs on the fate of organochlorine pesticides in sediments of the Yellow and East China seas. Geophys. Res. Lett. 2011, 38, No. L03602.

(60) Fang, Y.; Chen, Y.; Tian, C.; Lin, T.; Hu, L.; Li, J.; Zhang, G. Application of PMF receptor model merging with PAHs signatures for source apportionment of black carbon in the continental shelf surface sediments of the Bohai and Yellow Seas, China. J. Geophys. Res.: Oceans 2016, 121, 1346-1359. 
(61) Coppola, A. I.; Ziolkowski, L. A.; Masiello, C. A.; Druffel, E. R. $\mathrm{M}$. Aged black carbon in marine sediments and sinking particles. Geophys. Res. Lett. 2014, 41, 2427-2433.

(62) Masiello, C.; Louchouarn, P. Fire in the Ocean. Science 2013, 340, 287-288.

(63) Dittmar, T.; Paeng, J. A heat-induced molecular signature in marine dissolved organic matter. Nat. Geosci. 2009, 2, 175-179.

(64) Khan, A. L.; Wagner, S.; Jaffe, R.; Xian, P.; Williams, M.; Armstrong, R.; McKnight, D. Dissolved black carbon in the global cryosphere: Concentrations and chemical signatures. Geophys. Res. Lett. 2017, 44, 6226-6234.

(65) Wagner, S.; Brantley, S.; Stuber, S.; Van Stan, J.; Whitetree, A.; Stubbins, A. Dissolved black carbon in throughfall and stemflow in a fire-managed longleaf pine woodland. Biogeochemistry 2019, 146, 191-207.

(66) Gustafsson, Ö.; Kruså, M.; Zencak, Z.; Sheesley, R. J.; Granat, L.; Engström, E.; Praveen, P. S.; Rao, P. S. P.; Leck, C.; Rodhe, H. Brown Clouds over South Asia: Biomass or Fossil Fuel Combustion? Science 2009, 323, 495-498. 